\title{
The 'Excellence in Research for Australia' Scheme: A Test Drive of Draft Journal Weights with New Zealand Data
}

\author{
DAVID L. ANDERSON AND JOHN TRESSLER ${ }^{1}$
}

\section{Abstract}

The paper assesses the draft weighting system used by the Excellence in Research for Australia (ERA) scheme for measuring the output of refereed economics journal articles. It does so by using data from New Zealand's economics departments to demonstrate how the rankings of departmental and individual researchers are affected by the use of ERA weights rather than alternative weights employed in the economics literature. It concludes that the draft version of the ERA scheme, as released in August 2008, rewards research quantity over research quality, as traditionally defined.

\section{Introduction}

In February 2008, the Australian government announced its intention to develop a new quality and evaluation system for research conducted at the nation's universities. ${ }^{2}$ The scheme — 'Excellence in Research for Australia' (ERA) — will be based on a combination of bibliometric techniques and peer judgement; unlike most government-wide research-evaluation schemes employed internationally, it will not be used to allocate research funding. ${ }^{3}$ However, it defies reason to think that the scheme, given its complexity and aims, will not be used at some point to allocate, directly or indirectly, research funding. Although the ERA

\footnotetext{
1 Contact for correspondence, John Tressler, Economics Department, University of Waikato; tressler@ waikato.ac.nz.

2 See Australian Research Council (2008), 'New ERA for Research Quality: Announcement of Excellence in Research for Australia Initiative', Media Release, 28 February.

3 For details on the scheme, see the ERA's official website (www.arc.gov.au/era). The information reported in this paper is based on website details as at 21 April 2009.
} 
scheme will utilise several measures to evaluate institutional performance, we have chosen to focus on one element only: the assessment of refereed journalarticle output based on ERA's own journal-weighting scheme.

The results of the ERA exercise will only be reported at the discipline and institutional level; however, if universities are to implement plans to improve their performance, they will track the activity measures back to individual responsibility centres such as the academic department. Furthermore, if individual departments are to take steps to design strategies to improve performance over time, they will focus on the publication and citation records of the individual researcher. We must stress the last point since the official ERA line is that the research-evaluation scheme is not based on individual assessment. This is technically correct, but in practice the individual researcher is the basic building block of the scheme and hence will be under pressure to perform.

Therefore, for both the academic department and academic staff members, the nature of the journal-specific weighting scheme is of some importance. The ERA weighting scheme will undoubtedly shape the reward structure facing university administrators and individual academics. Our objective is to explore the nature of the ERA weighting scheme for economics, and to demonstrate how it impacts on departmental and individual researcher rankings relative to rankings generated by alternative schemes employed in the economics literature. In order to do so, we utilise data from New Zealand's economics departments and the draft set of journal weights (ERA) released in August 2008 by ERA officials. Given the similarities between Australia and New Zealand, our findings should have relevance to the Australian scene. As a result, we hope to provide the reader with a better understanding of the type of research activity that influences ERA rankings at both the departmental and individual level.

This paper assesses the draft weighting system used by the Excellence in Research for Australia (ERA) scheme for measuring the output of refereed economic-journal articles. We do so by using data from New Zealand's economics departments to demonstrate how the rankings of departmental and individual researchers are affected by the use of ERA weights rather than alternative weights employed in the economics literature. We show that the proposed journal weights are 'low-powered' by international standards. Partly, this results from the generous weights allocated by ERA to Australian-based journals. In summary, we demonstrate that the draft version of the ERA scheme rewards research quantity over research quality as traditionally defined. 


\section{The Literature on Ranking Research Output}

The economics literature on the ranking of economics departments is extensive. Although much of the early work was US-based, in more recent times research measurement and ranking studies have been conducted for many countries. ${ }^{4}$ The first rigorous study of Australian economics departments was conducted by Harris (1988). Harris arbitrarily developed a complex weighting system for virtually all forms of academic research output. This was followed by several studies based, in part, on citation counts. Towe and Wright (1995) placed 78 journals in three categories and then developed rankings of all Australian economics departments for each category. They also developed an overall ranking but implicitly assumed that all categories were of equal value. Subsequent work by Promfret and Wang (2003), Neri and Rogers (2006 and 2007), Macri and Sinha (2002, 2004, 2006, and 2008), and Sinha, Macri and McAleer (2009), employed various journal-based weighting schemes to rank Australia's economics departments and, in some cases, individuals. ${ }^{5}$

Of particular relevance to our study are three papers authored by Macri and Sinha: in these papers they incorporated New Zealand institutions into their analysis. ${ }^{6}$ Although Macri and Sinha (and, in one case, with McAleer) generally found Australian institutions to occupy the top positions in their per-capita rankings, the average performance of New Zealand's economics departments generally matched those of their Australian counterparts. For example, Macri and Sinha (2006) derived per-capita rankings for 31 university economics departments: seven in New Zealand and 24 in Australia. Their overall ranking placed New Zealand institutions solidly in the middle of the pack: Canterbury (9), Otago (11), Auckland (12), Waikato (16), Victoria (19), Massey (22) and Lincoln (28). ${ }^{7}$ Although Australian departments occupied the top eight positions, New Zealand departments performed slightly better overall (a mean rank score of 16.36 versus 17.20 for Australian departments). ${ }^{8}$ This suggests that using New Zealand data to test the ERA journal-weighting system should yield relevant results for Australian policymakers and university administrators.

There is another reason for using New Zealand, rather than Australian, data for testing the impact of ERA journal weights on departmental and individual rankings: independence. The discipline-specific weights are derived from a

\footnotetext{
4 For a good overview of the economics department-related ranking literature, see Liner and Amin (2004) and Macri and Sinha (2006).

5 For alternative approaches to ranking Australian economics departments, see Abbott and Doucouliagos (2003); Rodgers and Valadkhani (2006); and Rodgers and Neri (2007).

6 The relevant papers are: Macri and Sinha (2006); Sinha and Macri (2009) and Sinha, Macri and McAleer (2009).

7 The Auckland University of Technology (AUT) is not in the Macri and Sinha study due to the fact that the institution did not obtain university status until after the start of the sample period.

8 See Macri and Sinha (2006: 135-6).
} 
committee process that is based, in part, on advice provided by other academic groups. Given that many, if not most, of the members of these groups were Australian academics, it is plausible to suggest that some degree of game playing may have taken place in the journal selection and allocation process.

\section{Journal Data}

Our dataset covers all of New Zealand's academic economists on staff at its eight universities as of 15 April 2007, and we have collected information on each researcher's publication record over the six-year period beginning on 1 January 2001 and ending 31 December 2006. ${ }^{9}$ It should be noted that relevant publications have been defined to be refereed articles in journals listed in EconLit as at 15 April 2007 (1217 in number). In total, we found that 102 of New Zealand's 139 academic economists published 589 refereed papers in EconLitlisted journals (in whole or in part) over the relevant time period.

We have followed prevailing practice by allocating author shares on multipleauthored papers by utilizing the $1 / n$ rule, where $n$ is the number of authors. Although the ERA scheme gives preferential weighting to papers with multiple authors, if one or more of the authors are from different institutions, we can find no justification in the literature for doing so. Our decision to use the $1 / n$ allocation rule is based on the premise that journal editors (and reviewers) do not take into account the number of authors on a paper when making their decision to accept or reject it.

The second allocation decision to be faced relates to the process of allocating papers to specific institutions. Under the Stock method, one allocates all of a given researcher's output to her/his employer at the census date (in this case, 15 April 2007) regardless of where the work was performed. The Flow method, on the other hand, assigns journal articles to a researcher's employer either at the time of publication or when the paper was completed. We have adopted the Stock method since it gives a better indication of a department's current and short- to medium-term research capability. Under the Flow method, a department may have been strong in the past, but may now employ few of its past stars. Indeed, it should be noted that virtually all studies in Australia and New Zealand are based on the Stock method of output allocation; ${ }^{10}$ furthermore, the ERA scheme is also based on this method of allocation.

\footnotetext{
9 A six-year time period has been chosen since it is the assessment period adopted by the ERA scheme for measuring research activity. It is also the relevant time span adopted by the UK's Research Assessment Exercise (RAE) and NZ's Performance Based Research Funding (PBRF) scheme.

10 The exception is the work of Neri and Rodgers (2006 and 2007).
} 
Once again, we follow convention, and adopt the 'share-adjusted, weighted page' as our unit of output. Our share-adjustment process was described above, but the 'weighted page' requires an explanation. We adjust for pagesize differentials between journals, with the average-size $A E R$ page being the reference point and assigned a value of 1 . The page-size differences for 171 journals have been addressed by applying correction factors derived by Towe and Wright (1995) and Gibson (2000). For papers in all other EconLit-referenced journals (69 in total), we have used the average value derived by Gibson for his residual category journals; more explicitly, pages in such journals are assumed to contain 0.72 as many words as an average AER page.

\section{Weighting Schemes}

The draft ERA journal-weighting scheme (ERA) was developed by a committee of the Australian Research Council (ARC); this group chose a large number of relevant academic journals, and allocated them to one of four categories. ${ }^{11}$ The top journals were classified as ' $\mathrm{A}+$ ', the next best an ' $\mathrm{A}$ ', followed by ' $\mathrm{B}$ ' and ' $\mathrm{C}$ ' groupings. According to the ERA website, recognised journals were to be designated as follows: the top 5 per cent as ' $\mathrm{A}+$ ', the next 15 per cent as ' $\mathrm{A}$ ', the next 30 per cent as ' $\mathrm{B}$ ', and the remaining 50 per cent as ' $\mathrm{C}$ '. In the case of Economics, 611 journals were recognised as research-relevant, and the actual percentage of journals assigned 'A + ' through ' $\mathrm{C}$ ' were 6.9, 16.0, 32.3 and 44.8, respectively. In order to arrive at the stated purpose of ranking academic units, numerical grades must be given to the ' $\mathrm{A}+$ ' to ' $\mathrm{C}$ ' classification system.

For the purposes of this paper, we assign a grade of ' 4 ' to an 'A+', and so on to a ' 1 ' for a ' $\mathrm{C}$ '. In addition, economics journals not officially recognised by the ERA scheme, but listed in EconLit, are given a grade of ' 0 '. Therefore, in reality, the ERA ranking scheme is based on a five-point scale. We must stress that these are our weights, not those of the ERA scheme. Probably in order to avoid being responsible for a 'government'-sanctioned rating scheme, the developers of the ERA scheme stress that the information provided to the final decision-making group (Research Assessment Committee (RAC)) will not be aggregated. This means that the committee members will, by necessity, assign their own weights to each evaluation category. However, if the system is to be transparent, and if it is to be used eventually to allocate research funding, it is difficult to imagine that official weights will not be developed. We have chosen our weighting scheme

11 We must stress that we are testing the draft version of the ERA journal weights for economics. As noted earlier, according to the ERA's website, as at 21 April 2009, the final version is expected to be released in late 2009. 
based on academic convention - a version of the traditional weighting scheme employed by many universities, especially in North America, for converting from letter to numerical grades.

In order to provide the reader with a frame of reference, we have selected four journal-based weighting schemes that have been used by economists to rank economics departments. The set of possibilities is large, so in order to keep the discussion manageable we have arbitrarily selected two schemes from each of the so-called 'high-power' and 'low-power' camps. By 'high-powered' we have in mind schemes that discriminate significantly between the very best and lesser-quality journals. In such schemes, the top journals sometimes receive weights that are 1000 times or more the weight allocated to the lowest-ranked journals. It is quite common to find, say, the thirtieth-ranked journal receiving only 10-20 per cent of the weight accorded to the top journal. Such systems are based on the pioneering work of Liebowitz and Palmer (1984), and are generally known as 'impact-adjusted citation' measures. Liebowitz and Palmer's work was updated and refined by Laband and Piette (1994); Kalaitzidakis, Mamuneas and Stengos (2003); and Kodrzycki and Yu (2006).

We have chosen to use Kalaitzidakis, Mamuneas and Stengos (KMS) weights because they are well known in the rankings community and are based on more recent citation counts than Liebowitz and Palmer (1984) and Laband and Piette (1994). On the other hand, although the Kodrzycki and Yu (2006) weights (henceforth denoted as KY weights) are based on more recent citation counts than KMS, we have chosen to employ the KMS scheme for the following reasons. First, to date, the KY weighting scheme has not been widely used in ranking studies; ${ }^{12}$ and second, in a thorough evaluation of the characteristics of the KMS and KY schemes, Henrekson and Waldenstrom (2007) found the former to discriminate more sharply between high- and low-ranked performers. Given that our purpose is to demonstrate the differences in outcomes between using a generally accepted, aggressive weighting scheme and those generated by ERA weights, the KMS scheme is deemed to be appropriate. ${ }^{13}$

Given the recent expansion of the citation-counting industry, several up-to-date weighting schemes, based on a variant of the 'impact-adjusted citation' method, are available for selection. We have chosen to use the 'recursive discounted impact factors' derived by RePEc (Research Papers in Economics), as displayed on their website on 23 January $2009 .{ }^{14}$ Not only is this scheme based on recent

12 The only paper we found that did so was that by Henrekson and Waldenstrom (2007).

13 In some respects, KMS stands out as first amongst equals in the rankings literature. For example, Macri and Sinha (2006) refer to it as the 'industry standard', and, although in disagreement, Henrekson and Waldenstrom (2007) state that the scheme is held in high regard by many influential economists.

14 For details, see the organisation's website (http://repec.org) and Zimmermann (2007). 
citation activity, it also covers a broader range of journals than KMS (540 versus 143). However, it must be stressed that this weighting scheme is still officially at the experimental stage of development.

At the other extreme, we have arbitrarily selected two schemes that we have labelled as 'low-powered'. The most radical scheme is denoted as EQUAL; this implies that all journals listed in EconLit, as at 15 April 2007 are of equal value. That is, a page in, say, the $A E R$ is considered to be of equal value to a page in a newly established regional journal. In practice, the EQUAL weighting scheme yields a quantity rather than a quality indicator of research activity. However, it is included here in order to give the reader some idea of how closely the rankings generated by ERA correspond to those generated by an undifferentiated weighting system, and to shed some light on the underlying quantity-versus-quality debate.

Our second 'low-powered' scheme was derived by Bauwens (1998). Bauwens collected citation counts and derived simple impact factors for approximately 600 journals. He then multiplied the two results to generate a journal-specific score. Using an arbitrary allocation process, Bauwens assigned journals to one of five categories, with the highest ranking journals being given a ' 5 ', the next group a ' 4 ' and so on. Under the Bauwens scheme, 1.33 per cent of journals were placed in Group 5 and 7.64 per cent in Group 4. The corresponding figures for Group 3, Group 2 and Group 1 journals are 7.64, 7.64 and 75.75 per cent, respectively. ${ }^{15}$ All journals in EconLit for which impact factors could not be calculated were placed in Group 1. For this weighting scheme, the spread between the best journals and the worst ( 5 to 1 ) is roughly comparable to the ERA scheme wherein the spread is formally $4: 1$, but some EconLit-listed journals are unranked and thus receive a weight of ' 0 '.

Before proceeding to discuss our findings, we should address a possible reason for ERA being based on peer-review or perceptions rather than on more traditional bibliometric techniques. If the Australian government desires to encourage research on local and regional issues to improve the economic and social wellbeing of Australians, citations counts are not likely to yield journal weights that encourage such behaviour. ${ }^{16}$ Instead, they tend to be biased in favour of issues and subjects with a global appeal or to research with a large-countries or largeregion focus. For example, a study of labour issues in Tasmania is not likely to be as widely cited as an article of similar quality and methodology that focuses on the US or the EU. ${ }^{17}$

\footnotetext{
15 Bauwens notes that the equal number of journals in categories 4 to 2 is not intentional.

16 We wish to thank an anonymous reviewer for pointing out another reason for over-weighting domestic journals: to help foster dialogue between academics and the broader community by rewarding producers of readable, policy-oriented articles.

17 For a short discussion of this matter, in the Australian context, see Rodgers and Valadkhani (2006: 32).
} 
Agenda, Volume 16, Number 4, 2009

To address this problem, a number of researchers have arbitrarily added leading regional publications to their top journal lists. For example, see Harris (1988), KMS (1999), King (2001), Jin and Hong (2007), and Anderson and Tressler (2008). A somewhat different approach to addressing the issue was taken by Pomfret and Wang (2003): they acknowledged the importance of six Australian journals by considering them to be a separate category for output-determination purposes. The ARC committee has apparently followed the former approach rather extensively and perhaps aggressively.

\begin{tabular}{|c|c|c|c|c|c|c|c|c|}
\hline Journal Name & KMS & MSF & KYEI & CoupeIF & RePEc & LP84 & LP94 & ERA \\
\hline Agenda & NR & NR & NR & NR & NR & NR & NR & $\mathrm{A}$ \\
\hline \multicolumn{9}{|l|}{ Australian Ec. History } \\
\hline Review & 82 & NR & NR & 256 & NR & NR & NR & A \\
\hline Australian Ec. Papers & NR & NR & NR & NR & 285 & NR & NR & B \\
\hline Australian Ec. Review & NR & 104 & NR & NR & 248 & NR & NR & B \\
\hline \multicolumn{9}{|l|}{ Australian J of Agr and } \\
\hline Resource Ec. & 103 & 140 & 137 & 208 & 333 & 98 & 93 & A \\
\hline \multicolumn{9}{|l|}{ Australian Journal of Labour } \\
\hline Ec. & NR & NR & NR & NR & NR & NR & NR & B \\
\hline $\begin{array}{l}\text { Bulletin of Indonesian Ec. } \\
\quad \text { Studies }\end{array}$ & NR & NR & NR & 95 & 359 & NR & NR & $\mathrm{A}+$ \\
\hline Economic Analysis \& Policy & NR & NR & NR & NR & NR & NR & NR & $\mathrm{C}$ \\
\hline Economic Record & 58 & 88 & 133 & 232 & 208 & 65 & 85 & A \\
\hline \multicolumn{9}{|l|}{ History of Economics } \\
\hline Review & NR & NR & NR & NR & NR & NR & NR & B \\
\hline Pacific Economic Bulletin & NR & NR & NR & NR & NR & NR & NR & A \\
\hline Number of Journals Ranked & 143 & 150 & 181 & 273 & 540 & 108 & 101 & \\
\hline
\end{tabular}

Notes: NR (non-ranked); KMS (Kalaitzidakis, Mamuneas and Stengos (2003)); MSF (Mason, Steagall and Fabritius (1997)); CoupeIF (Coupe (2003), Impact Factors); KYEI (Kodrzycki and Yu (2006), Economic Impact Version); RePEc (Research Papers in Economics (2009)); LP84 (Liebowitz and Palmer (1984)); LP94 (Laband and Piette (1994)); and ERA (Excellence in Research for Australia (2008))

As shown in Table 1, the ERA scheme has placed most of Australia's EconLitlisted economics journals in a much higher category than that found in several widely used international classification systems. Note that only the Economic Record and the Australian Journal of Agriculture and Resource Economics are consistently ranked by the leading schemes, and even then they are found in the middle to lower-middle echelons. However, under the ERA, they are designated as 'A' journals. The other listed domestic journals are, in most cases, unranked internationally, but under the ERA they are frequently found in the 'A' and 'B' categories, and in the case of the Bulletin of Indonesian Economic Studies, in the 'A + ' classification. The above discussion is not to belittle these journals, but 
to point out to the reader that the ERA journal-weighting scheme aggressively attempts to offset the small-country bias of the pure citation-based ranking systems. ${ }^{18}$

\section{Departmental Results}

Before proceeding to discuss our findings, it should be noted that our results are presented in per-capita terms (output per eligible researcher) since it is our objective to determine productivity differences between departments. Our findings are presented in Tables 2 and 3. In the former, we present the standardised scores for each New Zealand economics department for each of our five weighting schemes. That is, the highest-scoring department has been given a score of '100', and all other raw scores are scaled accordingly. Therefore, a reported score in Table 2 of, say, 60.0 means that the average academic in that department produced 60 per cent as many 'share- and size-adjusted, weighted pages' as the average academic in the leading department.

Table 2: Standardized Scores; Per Capita Output; Share-Adjusted Weighted Pages New Zealand Economics Departments, 2001-2006

\begin{tabular}{llllll}
\hline & ERA & KMS & RePEc & Bauwens & EQUAL \\
Auckland & 61.86 & 100.00 & 100.00 & 64.09 & 46.42 \\
AUT & 20.18 & 4.40 & 3.32 & 19.94 & 24.83 \\
Canterbury & 62.64 & 53.94 & 89.09 & 73.02 & 68.50 \\
Lincoln & 46.06 & 14.27 & 13.28 & 48.67 & 53.97 \\
Massey & 43.04 & 10.82 & 12.88 & 44.58 & 50.13 \\
Otago & 100.00 & 53.96 & 74.28 & 100.00 & 85.97 \\
Victoria & 65.97 & 45.68 & 99.73 & 68.85 & 48.75 \\
Waikato & 90.08 & 19.62 & 46.97 & 97.28 & 100.00 \\
\hline
\end{tabular}

In Table 3 we provide the associated departmental rankings; for discussion purposes we shall focus on the latter table. Note that under our 'high-powered' schemes (KMS and RePEc) Auckland is the leader, with Canterbury, Otago and Victoria (especially under the RePEc scheme) all performing relatively well. ${ }^{19}$ On the other hand, Waikato finishes in fifth place under each of these schemes.

18 Given that we are using New Zealand data, we face a similar problem in how to treat the New Zealand Economic Papers, the leading economics journal in New Zealand. Following Anderson and Tressler (2008), we have given the New Zealand Economic Papers the same weight as the Economic Record throughout the study. The rationale is the same as that used by the ERA designers - the need to overcome the small-nation bias in citation-based schemes. Indeed, one might argue that the problem facing New Zealand journals is even more severe than that facing their Australian counterparts given the respective sizes of the two nations.

19 It must be noted that Peter Phillips, an internationally renowned economist, is not included in the Auckland data. We have restricted our dataset to academics holding 'regular' appointments at New Zealand universities. By 'regular' we mean an appointment akin to what in a North American setting would be called a 'tenure' or 'tenure track' position. A regular appointment need not be a full-time appointment. 
If we now move to look at our 'low-powered' schemes (Bauwens and EQUAL), we find that Waikato and Otago occupy either first or second place for each set of weights. Auckland now drops dramatically in the rankings, finishing in fifth and seventh place respectively under Bauwens and EQUAL. Under the ERA scheme, Otago leads the group, closely followed by Waikato, while Auckland holds fifth position. At this point it should be noted that for all of our weighting schemes, Lincoln, Massey and AUT always finish in fifth, seventh or eighth place, save for EQUAL.

Table 3:Rankings; Per Capita Output; Share-Adjusted Weighted Pages New Zealand Economics Departments, 2001-2006

\begin{tabular}{llllll}
\hline & ERA & KMS & RePEc & Bauwens & EQUAL \\
Auckland & 5 & 1 & 1 & 5 & 7 \\
AUT & 8 & 8 & 8 & 8 & 8 \\
Canterbury & 4 & 2 & 3 & 3 & 3 \\
Lincoln & 6 & 6 & 6 & 6 & 4 \\
Massey & 7 & 7 & 6 & 7 & 5 \\
Otago & 1 & 2 & 4 & 1 & 2 \\
Victoria & 3 & 4 & 2 & 4 & 6 \\
Waikato & 2 & 5 & 5 & 2 & 1 \\
\hline
\end{tabular}

It is apparent from the above discussion that ERA results are rather similar to those generated by Bauwens and EQUAL, and somewhat different from the KMS and RePEc rankings. ${ }^{20}$ This interpretation is reinforced by the information presented in Table 4. In this table we display the pair-wise correlation coefficients of the standardised scores between ERA and the other journal-based weighting regimes employed in this study. Note that ERA/Bauwens and ERA/EQUAL are highly correlated at 0.99 and 0.89 , respectively. On the other hand, the resulting pair-wise correlation coefficients for ERA/KMS (0.42) and ERA/KMS (0.59) are much weaker. ${ }^{21}$

We have focused our discussion on Otago, Waikato and Auckland in order to illustrate the underlying nature of the ERA scheme. Otago's results are rather insensitive to the weighting scheme used; they are first or second for every measure, save for a fourth-place finish under RePEc. Waikato also holds first or second place for all but our 'high-powered' schemes, but for these measures its

\footnotetext{
20 Some of the journals listed in EconLit as at 15 April 2007, and containing articles published by New Zealand economists over the period 2001-06, are considered to be finance journals by the ERA scheme. For these journals, we have used the relevant weights listed under the 'Banking, Finance \& Investment' heading. 21 The correlation coefficients reported in Table 4 are over the output scores shown in Table 3. Spearman correlation coefficients over ranks show a similar pattern: ERA/Bauwens (0.98), ERA/EQUAL (0.71), ERA/KMS (0.63) and ERA/RePEc (0.56).
} 
performance drops to fifth. The reverse applies to Auckland: first-place finishes under KMS and RePEc, but fifth place under ERA and Bauwens, and seventh under the EQUAL scheme.

Table 4: Correlation Coefficients over Standardised Output Scores, Various Weighting Schemes, NZ Economics Departments, 2001-2006

\begin{tabular}{llllll}
\hline & ERA & KMS & RePEc & Bauwens & Equal \\
ERA & 1.00 & 0.42 & 0.59 & 0.99 & 0.89 \\
KMS & 0.42 & 1.00 & 0.87 & 0.42 & 0.09 \\
RePEc & 0.59 & 0.87 & 1.00 & 0.61 & 0.27 \\
Bauwens & 0.99 & 0.42 & 0.61 & 1.00 & 0.91 \\
EQUAL & 0.89 & 0.09 & 0.27 & 0.91 & 1.00 \\
\hline
\end{tabular}

What accounts for these variable results, at least for Auckland and Waikato? First, it should be noted that Otago's strength is that its average output level is high (as evidenced by a second-place finish under EQUAL), and its researchers tend to publish in a broad mix of journals - a good proportion of which are highly valued by every weighting scheme in the study. In contrast, researchers at Auckland tend to publish relatively little (only AUT has a lower 'shareadjusted, unweighted page' output), but they tend to publish in mainstream international journals that are often highly ranked by 'impact-adjusted citation' schemes. The reverse holds for Waikato: active publishers, but often in lesserranked journals. In addition, Waikato-based researchers publish more widely in field- and policy-oriented journals than their Auckland counterparts.

As shown by our ERA results, the new Australian scheme can be said to favour Waikato-style activity rather than that displayed by Auckland-based researchers. One can also see why the ERA results favour high-volume over lowvolume producers by referring to Table 5. Note that over 50 per cent of the papers published by New Zealand-based economists are in 'A+'- or 'A'-ranked journals and 75 per cent of all such publications are in journals ranked ' $\mathrm{B}$ ' or above. ${ }^{22}$ The results for individual departments are rather striking: at Victoria 78 per cent of all publications are rated 'A' or above; the corresponding figure for Auckland is 64 per cent. Equally interesting is the fact that 92 per cent of the papers at Victoria and 86 per cent at Auckland are rated ' $\mathrm{B}$ ' or higher. However, we must remind the reader that the overall ERA leaders, Otago and Waikato, have production profiles that are more widely distributed across the ranking system,

22 As noted earlier, we have given the New Zealand Economic Papers (NZEP) the same weight as the Economic Record for all schemes employed in this analysis. However, the ERA official weighting is a ' $\mathrm{C}$ ', not an ' $\mathrm{A}$ ' as follows from our treatment of NZEP. Although it is difficult for us to imagine that if New Zealand officials were designing an ERA-like weighting scheme, that they would place NZEP in the ' $\mathrm{C}$ ' category, it is a possible outcome. If this were the case, the departmental rankings given above would not change, but the transfer of 38 publications from the ' $\mathrm{A}$ ' to the ' $\mathrm{C}$ ' category would obviously change the results presented in Table 3 . The overall percentage of papers in category ' $\mathrm{A}$ ' would decline from 39.0 to 32.0; and the percentage of papers in category ' $\mathrm{C}$ ' would increase from 12.2 to 19.1 . 
but they generate substantially more publications per capita than Victoria and Auckland. More specifically, although Otago and Waikato have only 53 and 44 per cent of their papers classified as ' $\mathrm{A}$ ' or above (still impressive numbers), they produce approximately twice as many refereed-journal pages per-capita.

\begin{tabular}{llllll}
$\begin{array}{l}\text { Table 5, Percentage Allocation of Economics Publications By ERA } \\
\text { Category }\end{array}$ & \multicolumn{1}{l}{$\begin{array}{l}\text { A } \\
\text { Ca }\end{array}$} & A & B & C & $X^{*}$ \\
Auckland & 23.7 & 40.8 & 19.7 & 7.9 & 7.9 \\
AUT & 10.0 & 10.0 & 40.0 & 20.0 & 20.0 \\
Canterbury & 14.1 & 36.6 & 21.1 & 4.2 & 23.9 \\
Lincoln & 3.6 & 39.3 & 5.4 & 41.1 & 10.7 \\
Massey & 2.5 & 29.1 & 30.4 & 17.7 & 20.3 \\
Otago & 12.8 & 40.4 & 33.0 & 6.4 & 7.4 \\
Victoria & 23.8 & 54.0 & 14.3 & 0.0 & 7.9 \\
Waikato & 5.0 & 39.0 & 25.0 & 13.0 & 18.0 \\
\hline Weighted Average & 11.8 & 39.0 & 23.0 & 12.2 & 14.0 \\
\hline ERA Scheme* & 6.9 & 16.0 & 32.3 & 44.8 & 0.0 \\
\hline
\end{tabular}

Notes: * $\mathrm{X}$ represents articles in journals not ranked by the ERA scheme.

** Percentage distribution of 'Economics' journals in each ERA category.

The above suggests that the ERA scheme is not, in practice, a very discriminating weighting system. This view is reinforced by the fact that 6.9 per cent of the journals ranked by ERA have been designated as 'A+' journals whereas 11.8 per cent of all publications by New Zealand economists in our study are to be found in this category. Our position that the ERA scheme is a 'low-powered' weighting scheme is further augmented by the following Gini coefficients: KMS (0.738), RePEc (0.663), Bauwens (0.306) and ERA (0.220). ${ }^{23}$

\section{Individual Results}

As noted previously, the formal ERA evaluation process does not rank individual researchers. However, given that individual research records are the basic building block of the scheme, it defies logic to think that such results will not be informally calculated and disseminated. That is, individual rankings are likely to be of interest to most members of Australia's academic departments since high rankings may generate pecuniary rewards. ${ }^{24}$ Highly ranked

23 These results are for ranked journals only. Under the KMS, RePEc and ERA schemes, some journals are not formally ranked, and we have assigned a weight of zero to such journals. If all zero-ranked journals are included in the analysis, the resulting Gini coefficients are as follows: KMS (0.898), RePEc (0.794), Bauwens (0.306) and ERA (0.412).

24 It should be noted that it will be relatively easy for individuals to calculate their own outputs, and that of their colleagues, since the two critical components of the calculation will be in the public domain: refereed 
performers will undoubtedly use such information in promotion applications and, where possible, in merit-pay requests. Even more importantly, highly ranked individuals will find themselves in demand in the recruiting market as some departments attempt to game the system and improve their relative performance. Such behaviour is quite likely in subsequent rounds of the ERA process. ${ }^{25}$ Rephrased, high rankings have economic value in addition to traditional psychic benefits such as bragging rights.

In Table 6 we display the results for the top 25 ERA performers, and provide the corresponding rank for these researchers under each of our four competing schemes. The overall message is clear: how one measures research output does matter at the individual level. It is apparent that, at least at the upper levels, ERA rankings are closely associated with our 'low-power' schemes (Bauwens and EQUAL) and are far less so with our 'high-power' regimes (KMS and RePEc). For example, consider the top five performers under the ERA. These very same individuals hold the top five spots under the Bauwens and EQUAL regimes. On the other hand, only one researcher in the ERA top five is in the same group under KMS. For RePEc the results are less extreme, with three of ERA's top five holding such scores, but the two other individuals in the RePEc top five hold the seventeenth and twenty-fifth positions in ERA, and the sixth-ranked ERA performer is thirty-fifth under the RePEc scheme. It should also be noted that only eight of the top 25 ranked economists by ERA are also in the top 25 for all other weighting schemes used in this study.

Although the above analysis is based on casual empiricism, it is supported by the relevant pair-wise correlation coefficients of the output scores for the ERA top twenty-five researchers. The results are as follows: ERA/KMS (0.049); ERA/RePEc (0.471); ERA/EQUAL (0.858) and ERA/Bauwens (0.948). The corresponding estimates for the full set of active researchers $(\mathrm{N}=102)$ are somewhat higher but still consistent with the above pattern: ERA/KMS (0.361); ERA/RePEc (0.598); ERA/EQUAL (0.897) and ERA/Bauwens (0.966). ${ }^{26}$ All of this suggests that many academics that have performed well under more traditional, internationally recognised weighting schemes may be surprised by their standing under the ERA scheme, and may find their economic value to Australian-based departments reduced.

publications in EconLit and the requisite weights from the ERA website.

25 However, such behaviour will be constrained by the desire of many academics for international mobility and acclaim, and knowledge that research-evaluation schemes may change radically over time.

26 Spearman correlation coefficients over the implied ranks for the top 25 economists as ranked by ERA are: ERA/KMS (0.27), ERA/RePEc (0.46), ERA/Bauwens (0.81) and ERA/EQUAL (0.87). The corresponding Spearman correlation coefficients for the full set of active researchers $(\mathrm{N}=102)$ are somewhat higher but still consistent with the preceding pattern: ERA/KMS (0.67), ERA/RePEc (0.69), ERA/Bauwens (0.94) and ERA/ EQUAL (0.90). 
Table 6:Individual Rank, Share-Adjusted Weighted Pages New Zealand Academic Economists, 2001-2006

\begin{tabular}{|c|c|c|c|c|c|c|c|}
\hline Last Name & First Name & Univ. & ERA & KMS & RePEC & Bauwens & EQUAL \\
\hline Gibson & John W & W & 1 & 11 & 5 & 3 & 3 \\
\hline Fielding & David & $\mathrm{O}$ & 2 & 10 & 4 & 1 & 2 \\
\hline Holmes & Mark & $\mathrm{W}$ & 3 & 34 & 25 & 4 & 1 \\
\hline Guthrie & Graeme & $\mathrm{V}$ & 4 & 2 & 1 & 2 & 5 \\
\hline McCann & Philip & W & 5 & 51 & 17 & 5 & 4 \\
\hline $\mathrm{Li}$ & Xiaoming & M & 6 & 29 & 35 & 6 & 7 \\
\hline Oxley & Les & $\mathrm{C}$ & 7 & 40 & 12 & 15 & 12 \\
\hline Ryan & Matthew & A & 8 & 5 & 22 & 14 & 21 \\
\hline Guender & Alfred V. & $\mathrm{C}$ & 9 & 12 & 10 & 8 & 8 \\
\hline McDermott & C. John & $\mathrm{V}$ & 10 & 18 & 27 & 9 & 17 \\
\hline Sul & Donggyu & A & 11 & 7 & 3 & 7 & 23 \\
\hline Gounder & Rukmani & $\mathrm{M}$ & 12 & 48 & 58 & 20 & 9 \\
\hline Haug & Alfred A. & $\mathrm{O}$ & 13 & 4 & 14 & 16 & 15 \\
\hline Knowles & Stephen & $\mathrm{O}$ & 14 & 24 & 34 & 10 & 20 \\
\hline Singleton & John & $\mathrm{V}$ & 15 & 53 & 95 & 36 & 13 \\
\hline Engelbrecht & Hans-Jurgen & M & 16 & 33 & 42 & 19 & 19 \\
\hline Bandyopadhyay & Debasis & A & 17 & 32 & 40 & 22 & 16 \\
\hline Vaithianathan & Rhema & A & 18 & 28 & 23 & 23 & 33 \\
\hline Hazledine & Tim & A & 19 & 61 & 44 & 31 & 32 \\
\hline Evans & Lewis & $\mathrm{V}$ & 20 & 35 & 38 & 26 & 26 \\
\hline Han & Chirok & A & 21 & 1 & 2 & 12 & 39 \\
\hline Bertram & Geoffrey & $\mathrm{V}$ & 22 & 36 & 41 & 17 & 25 \\
\hline Dalziel & Paul & $\mathrm{L}$ & 23 & 64 & 63 & 32 & 22 \\
\hline Reed & W. Robert & $\mathrm{C}$ & 24 & 13 & 13 & 18 & 24 \\
\hline Maloney & Tim & A & 25 & 30 & 31 & 30 & 35 \\
\hline
\end{tabular}

\section{Conclusion}

In this paper we have attempted to show the impact of using the draft journal weights of the ERA scheme on the reported performance of New Zealand's economics departments and individual researchers. The results are then contrasted with those generated by alternative weighting schemes arbitrarily selected to represent so-called 'high-' and 'low-powered' schemes. The findings suggest that the outcomes generated by the draft version of the ERA weights 
for economics journals (ERA) are quite similar to those generated by our 'lowpowered' schemes: EQUAL and Bauwens. This suggests that the ERA scheme does not aggressively differentiate between high- and low-quality journals.

Rephrased, articles in journals that are traditionally ranked highly in the economics literature continue to be highly ranked by the ERA, but they are joined by a number of other journals. Indeed, we found that over 50 per cent of the articles published by New Zealand economists over the 2001-2006 period were in what ERA deems to be 'A+' or 'A' journals.

Our analysis was retrospective: we applied the ERA scheme to past research activity. If, on the other hand, researchers are aware of the rankings and target submissions accordingly, the percentage of publications in the top classifications should increase. Although this may be socially useful in that more research on domestic issues is likely to be forthcoming, departmental scores will become more compressed and the rankings less stable.

At this point we must stress two major qualifications to our work. First, we have arbitrarily converted a letter grading scheme to a numerical one: recall that we assigned an 'A+' a grade of ' 4 ', an 'A' a grade of ' 3 ' and so on. Clearly this may not be the implicit grading scheme used by the Research Assessment Committee of the ERA, but word of mouth will eventually occur to give academic researchers some idea of the prevailing norms. We have adopted a somewhat similar strategy: we have used the traditional conversion scheme used by many academic administrators to convert letter grades to numerical grades and vice versa. We believe our work is a useful starting point for evaluating the impact of using ERA journal weights on departmental and individual performance, and as an aid in helping administrators and researchers devise strategies to improve subsequent rankings

Our second qualification is straightforward. Following universal practice in the departmental rankings game, we have defined research to be refereed-journal articles only. This approach is largely adopted for pragmatic reasons, and it undoubtedly penalises those who prefer to publish books and monographs, and engage in other scholarly activities.

Despite the above limitations, we believe our analysis is quite relevant to Australian economists and to department heads in Australian economics departments. As noted earlier, New Zealand economics departments may not perform as well as the top group of Australian institutions, but, on average, as calculated by Australian-based researchers, perform as well as their Australian counterparts. Furthermore, our findings suggest that some institutions that perform well under more conventional weighting schemes do not fare as well 
under the draft ERA journal-weighting scheme. Perhaps the traditional leaders in Australia may suffer a similar fate under the journal article component of the new national evaluation scheme.

\section{References}

Abbott, M. and Doucouliagos, C. 2003, 'The Efficiency of Australian Universities: A Data Envelopment Analysis', Economics of Education Review, 22(1): 89-97.

Anderson, David L. and Tressler, John 2008, 'Research Output in New Zealand Economics Departments 2000-2006: A Stock Approach', New Zealand Economic Papers 42(2): 155-89.

Bauwens, Luc 1998, 'A New Method to Rank University Research and Researchers in Economics in Belgium', unpublished paper, CORE, Universite Catholique de Louvain, Louvain, Belgium at: www.core.ucl.ac.be/econometrics/ bauwens/rankings/method.doc)

Coupe, T. 2003, 'Revealed Performances: Worldwide Rankings of Economists and Economics Departments, 1990-2000', Journal of the European Economic Association 1(6): 1309-45.

Gibson, John 2000, 'Research Productivity in New Zealand University Economics Departments: Comments and Update', New Zealand Economic Papers 34(1): 73-87.

Harris, G. T. 1988, ‘Research Output in Australia University Economics Departments, 1974-83', Australian Economic Papers 27(2): 102-10.

Harris, G. T. 1990, 'Research Output in Australian University Economics Departments: An Update for 1984-1988' Australian Economic Papers 29(4): 249-59.

Henrekson, Magnus and Waldenstrom, Daniel 2007, 'Should Research Performance be Measured Unidimensionally? Evidence from Rankings of Academic Economists', Research Institute of Industrial Economics, Working Paper No. 712, Stockholm, Sweden.Jin, Jang C. and Hong, Jin-Heon 2008, 'East Asian Rankings of Economics Departments', Journal of Asian Economics 19(1): 74-82.

Kalaitzidakis, Pantelis, Mamuneas, Theofanis and Stengos, Thanasis 1999, 'European Economics: An Analysis Based in Publications in the Core Journals', European Economic Review 44(6): 1150-68. 
Kalaitzidakis, Pantelis, Mamuneas, Theofanis and Stengos, Thanasis 2003, 'Rankings of Academic Journals and Institutions in Economics', Journal of the European Economic Association 1(6): 1346-66.

King, Ian 2001, 'Quality versus Quantity: Ranking Research Records of Economics Departments in New Zealand', New Zealand Economic Papers 35(2): 97-112.

Kodrzycki, Yolanda K. and Yu, Pingkang 2006, 'New Approaches to Ranking Economics Journals', B.E. Journals in Economic Analysis and Policy: Contributions to Economic Analysis and Policy 5 (1): 1-42.

Laband, David and Piette, Michael 1994, 'The Relative Impact of Economics Journals', Journal of Economic Literature 32(2): 640-66.

Liebowitz, S. J. and Palmer, J. P. 1984, 'Assessing the Relative Impact of Economics Journals', Journal of Economic Literature 22(1): 77-88.

Liner, Gaines H. and Amin, Minesh 2004, 'Methods of Ranking Economics Journals', Atlantic Economics Journal 32(2): 140-9.

Macri, Joseph and Sinha, Dipendra 2006, 'Rankings Methodology for International Comparisons of Institutions and Individuals: An Application to Economics in Australia and New Zealand', Journal of Economic Surveys 20(1): $111-56$.

Mason, Paul, Steagall, Jeffrey and Fabritius, Michael 1997, 'Economics Journal Rankings by Type of School: Perceptions versus Citations', Quarterly Journal of Business and Economics 36(1): 69-79.

Neri, Frank and Rodgers, Joan R. 2006 'Ranking Australian Economics Departments by Research Productivity', Economic Record 82 (Special Issue): 74-84.

Pomfret, Richard and Wang, Liang Choon 2003 'Evaluating the Research Output of Australian Universities' Economics Departments', Australian Economic Papers 42(4): 418-41.

Rodgers, Joan R. and Valadkhani, Abbas 2006, 'A Multidimensional Ranking of Australian Economics Departments', Economic Record 82(256): 30-43.

Rodgers, Joan R. and Neri, Frank 2007, 'Research Productivity of Australian Academic Economists: Human-Capital and Fixed Effects', Australian Economic Papers 46(1): 67-87.

Sinha, Dipendra and Macri, Joseph 2002, 'Rankings of Australian Economics Departments, 1988-2000', Economic Record 78(241): 136-46. 
Sinha, Dipendra and Macri, Joseph 2004, 'Rankings of Economists in Teaching Economics Departments in Australia 1988-2000', Economics Bulletin 1(4): $1-19$.

Sinha, Dipendra and Macri, Joseph 2009, ‘How Much Influence Do Economics Professors Have on Rankings? The Case of Australia and New Zealand', Applied Economics (forthcoming).

Sinha, Dipendra, Macri, Joseph and McAleer, Michael 2009, 'On the Robustness of Alternative Rankings Methodologies: Australian and New Zealand Economics Departments, 1988-2002', Applied Economics (forthcoming).

Towe, Jack B. and Wright, Donald J. 1995, 'Research Published by Australian Economics and Econometrics Departments: 1988-93', Economic Record 71(212): 8-17.

Zimmermann, Christian 2007, 'Academic Rankings with RePEc', Working Paper 2007-36, Department of Economics, University of Connecticut. 